\title{
Specificity of anti-Sm antibodies by ELISA for systemic lupus erythematosus: increased sensitivity detection using purified peptide antigens
}

\author{
M FiELD, D G WILliaMS, P CHARLES, AND R N MAINI \\ From the Clinical Immunology Division, Kennedy Institute of Rheumatology, Hammersmith, London
}

SUMMARY $\mathrm{Sm}$ antigen was purified by immunoaffinity chromatography using a murine monoclonal anti-Sm antibody and was confirmed to be free from contaminating polypeptides This was then used to detect anti-Sm antibodies in patients' sera by enzyme linked immuno $-\overrightarrow{0}$ sorbent assay (ELISA). Antibodies against Sm were detected in only 9/52 (17\%) patients witlipo systemic lupus erythematosus (SLE) by immunodiffusion, but $15 / 52(29 \%)$ were positive for IgCo anti-Sm antibodies by ELISA. The presence of anti-Sm antibodies remained disease specifie despite the increase in sensitivity of this assay and validates its potential use for clinicat application. There was no correlation between the presence of anti-Sm antibodies and any clinical features of SLE. In 23 renal biopsies a membranous component to the glomerulonephritios correlated with anti-Sm antibodies $(\mathrm{p}<0 \cdot 05)$. Patients from West Africa, the Carribean Islands, and Asia had a higher prevalence of anti-Sm antibodies than the local Caucasian populatiog

The overproduction of autoantibodies against nuclear antigens is a cardinal feature of systemic lupus erythematosus (SLE). Those against native double stranded DNA are regarded as pathognomic of this disorder. When originally described, antibodies against the nuclear antigen Sm were also considered diagnostic of SLE, ${ }^{1}$ but more sensitive techniques suggested that they may be more widely distributed in autoimmune disease. ${ }^{2}$

These initial discrepant results arose partly because of poor understanding of antigen structure. Mattioli and Reichlin showed that the Sm antigen could exist as a free moiety or in a complex with another ribonucleoprotein antigen, RNP. ${ }^{3}$ Hence antibodies to either component of the RNP/Sm antigen could have produced positive results in early assays.

Later studies showed that the Sm antigen could be separated from the RNP/Sm complex by affinity chromatography. ${ }^{4}$ The advent of murine monoclonal anti-Sm antibodies led to the adaptation of this technique to enable characterisation of the RNA and protein components of the $\mathrm{Sm}$ antigen. ${ }^{5}$ Immunoblotting analysis with these antibodies ${ }^{6}$ has

Accepted for publication 9 March 1988.

Correspondence to Dr M Field, Clinical Immunology Division, Kennedy Institute of Rheumatology, 6 Bute Gardens, Hammersmith, London W6 7DW. confirmed that the antigenic determinants reside on the protein moieties.

The aim of this study was to use a murine्ष monoclonal anti-Sm antibody to obtain highly purio fied $\mathrm{Sm}$ antigen by affinity chromatography for us $\overrightarrow{0}$ in an ELISA. Serum samples from patients with autoimmune diseases were analysed for the pre? sence of anti-Sm antibodies to investigate theip. diagnostic specificity for SLE. The clinical feature of all patients were analysed to assess whether the presence of anti-Sm antibodies predisposes to ang specific disease manifestations.

\section{Patients and methods}

Sm was purified by a modified method of Buchanan et al. ${ }^{4}$ Affinity chromatography columns were made by coupling purified IgG to cyanogen bromideु activated Sepharose beads (Pharmacia, Miltop Keynes, Buckinghamshire). Rabbit thymus extrace (Pelfreeze Biologicals, Arkansas, USA) was ex ${ }^{\omega}$ tracted ( $2 \%$ weight/volume) by sonication for on minute (Soniprep; MSE Scientific Instrument Crawley, Sussex) in $0.1 \mathrm{M}$ glycine containing $0.35 \mathrm{M}$ $\mathrm{NaCl}, 10 \mathrm{mM}$ trometamol (TRIS), and $0.1 \mathrm{mM}^{+}$

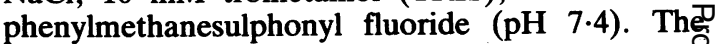
insoluble fraction was separated by centrifugation a $4000 \mathrm{~g}$. 
The soluble fraction was initially applied to a column made with normal human IgG, and the drop through was sequentially passed down a column containing IgG from a patient with high titre monospecific anti-RNP antibody and then down the column made with the murine monoclonal anti-Sm antibody (KSm2). Each column was separated, washed, and eluted with $3 \mathrm{M}$ guanidinium hydrochloride (Sigma, Poole, Dorset). Fractions with the highest optical density at $280 \mathrm{~nm}$ were pooled, dialysed against phosphate buffered saline (PBS), and stored at $0^{\circ} \mathrm{C}$. Each extraction yielded $1-1.5 \mathrm{mg}$

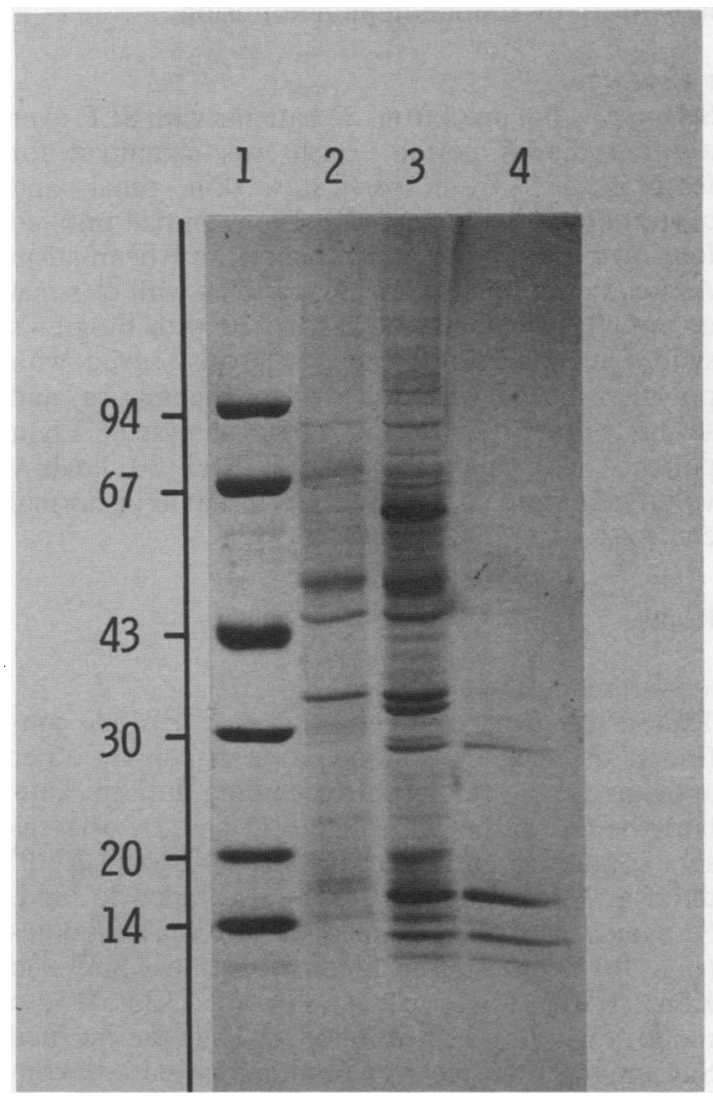

Fig. 1 Sodium dodecyl sulphate-polyacrylamide gel electrophoresis of the eluates from the immunoaffinity columns; comparison with the molecular weight standards (mol. wt 94, 67, 43, 30, 20.1, 14.4 kilodaltons) in lane 1. Lane 2 shows the eluate from the normal IgG column. Lane 3 shows the eluate from the anti-RNP column with multiple bands including RNP bands at 67 and 33 and Sm bands at 29, 28,16, and three bands at 13-11 kilodaltons. Lane 4 shows the purified Sm antigen from the monoclonal antibody and shows only the Sm specific bands. of pure $\mathrm{Sm}$ antigen from $2 \mathrm{~g}$ of rabbit thymus extract.

\section{POLYPEPTIDE ANALYSIS}

The purified protein antigens were analysed by sodium dodecyl sulphate-polyacrylamide gel electrophoresis (SDS-PAGE) ${ }^{7}$ modified according to Williams et al. ${ }^{6}$ The separated proteins were stained with Coomassie blue (Fig. 1).

The $\mathrm{Sm}$ antigen was also screened by ELISA (which see) using two murine monoclonal antibodies $^{6}$ directed against the 29, 28 kilodalton doublet (KSm5) or the 16 kilodalton (KSm2) components of the $\mathrm{Sm}$ antigen to ensure both proteins were present in the purified antigen.

ANTI-Sm ANTIBODY DETECTION

Purified Sm antigen $(30 \mu \mathrm{g} / \mathrm{ml})$ was coated onto ELISA plates (Nunc Immunoplate, Roskilde, Denmark), incubated at $4^{\circ} \mathrm{C}$ overnight, washed with PBS, and incubated with $2 \%$ casein (Fisons, Loughborough, Leicestershire) for 60 minutes at $37^{\circ} \mathrm{C}$. The plate was then washed in $0 \cdot 1 \%$ Tween in PBS (PBS/Tween) six times. All subsequent incubations and washes were performed similarly.

Each sample was assayed for anti-Sm antibodies by diluting $1: 300$ in $0.5 \%$ casein in PBS/Tween and applying $50 \mu \mathrm{l}$ aliquots to individual wells. The plate was then incubated, washed, and bound IgG antibody detected using an antihuman (or antimouse when screening the monoclonal antibodies) IgG conjugate linked to alkaline phosphatase (Sigma, Poole, Dorset). The enzyme was detected with p-nitrophenyl phosphate (Substrate 104; Sigma, Poole, Dorset) and the optical density of each sample read at $405 \mathrm{~nm}$ in a Titertek multiscan spectrophotometer (Flow Laboratories, Rickmansworth, Hertfordshire).

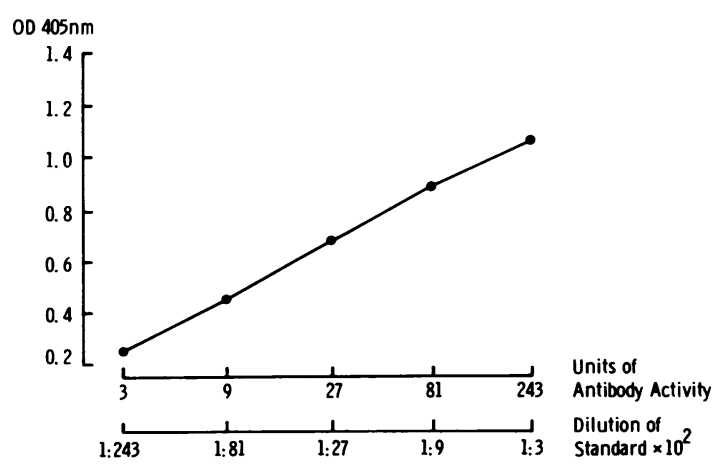

Fig. 2 The construction of the standard curve for the measurement of anti-Sm antibodies (for details see text). 


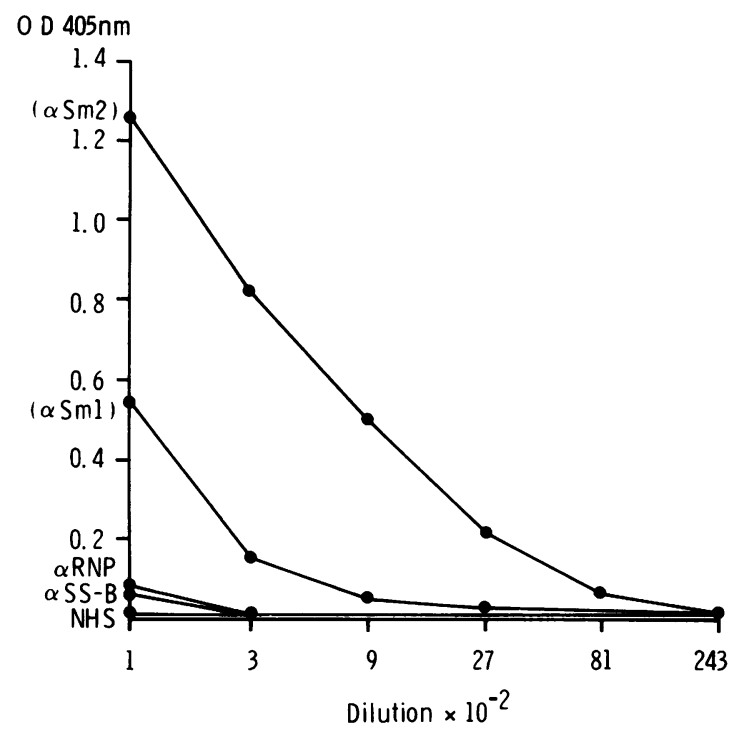

Fig. 3a

$0.0405 \mathrm{~nm}$

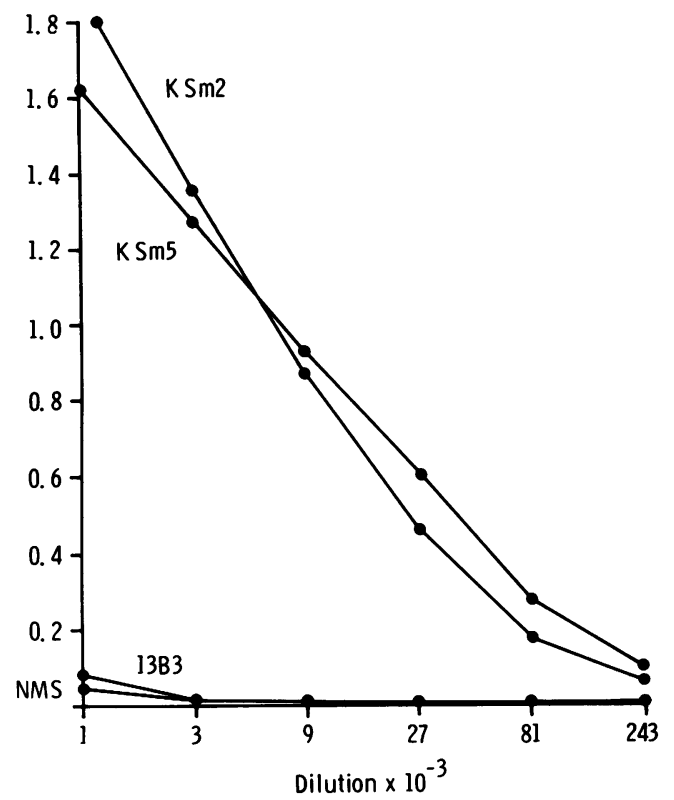

Fig. 3b

Fig. 3 Results from representative ELISA experiments using (a) human sera of defined specificity, demonstrating positive results with serum containing anti-Sm antibody, whereas those with anti-RNP, anti-SS-B activity, and normal human serum do not bind, and (b) murine monoclonal antibodies (KSm5 reacting with the 29, 28 kilodalton doublet and $\mathrm{KSm} 2$ binding to the 16 kilodalton $S m$ antigen) showing binding, whereas those with anti-SS-B activity (13B3/SW5) and normal mouse serum (NMS) do not bind.
The optical density of each sample was compared $\frac{\overline{5}}{3}$ with a standard curve obtained by diluting a mono- $\frac{}{n}$ specific serum containing a high titre of anti-Sm? antibodies. This was diluted threefold from 1:100 to $\overrightarrow{\bar{s}}$ 1:24 300 on each plate (Fig. 2). The lowest optical density obtained for a dilution of 1:24 300 was arbitrarily allocated a value of 3 ELISA units, that $\bar{\omega}$ for the dilution of 1:8100-9 units, increasing up the $\mathbb{\Phi}$ dilution scale so that the value for the 1:300 dilution was ascribed 243 units. For those serum samples ${ }^{\text {क }}$ producing results above the standard curve a dilution $\vec{\circ}$ was made and appropriate correction calculated to $\vec{A}$ obtain the result for the standard dilution. All $\omega_{\overparen{\omega}}$ results were compared with those obtained in the laboratory by routine immunodiffusion.

\section{PATIENTS}

Serum was obtained from 52 patients with SLE over 0 a three month period. Each was examined for 0 features of SLE, in particular, skin, renal, and 9 central nervous system dysfunction, and all fulfilled four or more criteria of the American Rheumatism $O$ Association. ${ }^{8}$ In addition, 53 patients with classicalo or definite rheumatoid arthritis, 20 with Sjögren's $\Phi$ syndrome, 30 with systemic sclerosis, seven with $\overrightarrow{.}$ polymyositis, 12 with polymyalgia rheumatica, aggd $\infty$ seven with osteoarthritis were analysed. Eight. patients with multiple sclerosis and 30 healti volunteers were also screened as diseased or norma्al controls.

\section{Results}

ANTIGEN ANALYSIS

The results from one representative ELISA confirmed the lack of contamination of Sm by other antigens (Fig. 3a). Serum containing anti-Sm antibody bound to the $\mathrm{Sm}$ antigens (1 and 2 ), whereas sera containing antibodies against $\mathrm{SS}-\mathrm{B}^{3}$ and $\mathrm{RNP}^{5}$ did not. Normal human serum also failed to bind. Screening with the monoclonal anti-Sm antibodies (Fig. 3b) demonstrated binding of both $\mathrm{KSm} 5$ and $\mathrm{O}$ $\mathrm{KSm} 2{ }^{6}$ There was no binding of $13 \mathrm{~B} 3 / \mathrm{SW} 5$, a? monoclonal anti-SS-B antibody. ${ }^{9}$ Thus the purified Sm antigen was free from contamination and contained both the 29,28 kilodalton doublet and the $16 \%$ kilodalton epitopes.

SDS-PAGE analysis of the eluate from the antibody columns confirmed the sequential purifica- $\omega$ tion of the $\mathrm{Sm}$ antigens. The normal IgG column eluate contained some bands purified non-은

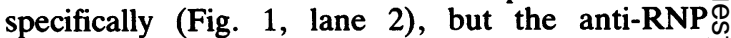
column purified both the 67 and 33 kilodalton bands ${ }^{-}$ of RNP together with the $29,28,16,13$, and $11-$ kilodalton Sm polypeptides but also contained many $\vec{\Phi}$ contaminating bands (Fig. 1, lane 3). The anti-Sm $\frac{\rho}{\mathbb{Q}}$ 
column eluate, however, contained solely the Sm proteins (Fig. 1, lane 4) and had no significant contaminating polypeptides.

DETECTION OF ANTI-Sm ANTIBODIES

In a single time point assay anti-Sm antibodies were detected in 15 patients with SLE (29\%) and not in sera from patients with other connective tissue diseases or normal controls (Fig. 4). Comparison of the results obtained by ELISA and immunodiffusion demonstrated broad agreement between the two assays as the patients with higher titre by immunodiffusion tended to have a high titre by ELISA (Table 1). Six patients with SLE, however, had antiSm antibodies detectable solely by ELISA.

After a retrospective analysis of all 52 patients a further three had anti-Sm antibodies making a total of $18(35 \%)$. Of the 45 women, 15 were positive $(33 \%)$, as were three of the seven male patients $(43 \%)$. Analysis by racial subgroups demonstrated seven patients positive out of 34 Caucasians (21\%),

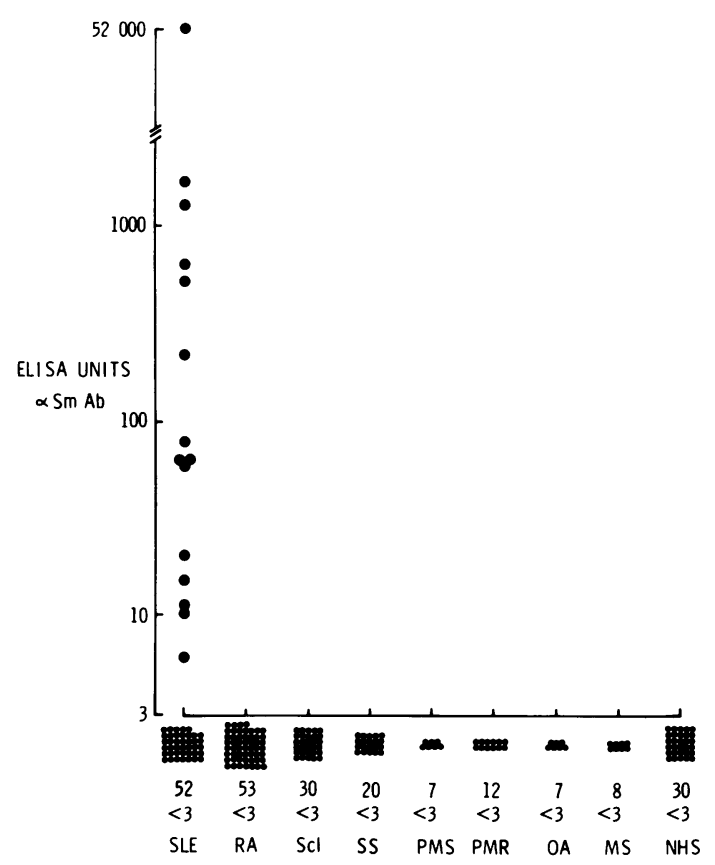

Fig. 4 The prevalence of anti-Sm antibodies in a variety of autoimmune and connective tissue diseases demonstrating their restriction to SLE. $S L E=$ systemic lupus erythematosus; $R A=$ rheumatoid arthritis; $S c l=$ sclerosis; $S S=$ Sjögren's syndrome; $P M S=$ polymyositis; $P M R=$ polymyalgia rheumatica; $O A=$ osteoarthritis; $M S=$ multiple sclerosis;

NHS = normal human serum.
Table 1 Anti-Sm antibodies detected by ELISA and immunodiffusion

\begin{tabular}{lrl}
\hline Patient No & $\begin{array}{c}\text { ELISA } \\
\text { (units) }^{*}\end{array}$ & $\begin{array}{l}\text { Immunodiffusion } \\
\text { (dilution) }{ }^{\dagger}\end{array}$ \\
\hline 1 & 52650 & $>1: 64$ \\
2 & 1647 & Neg \\
3 & 1273 & $1: 4$ \\
4 & 630 & $1: 1$ \\
5 & 531 & Neg \\
6 & 282 & $1: 4$ \\
7 & 78 & $1: 4$ \\
8 & 63 & $1: 1$ \\
9 & 62 & $1: 4$ \\
10 & 58 & $1: 4$ \\
11 & 46 & Neg \\
12 & 20 & $1: 1$ \\
13 & 15 & Neg \\
14 & 10 & Neg \\
15 & 6 & Neg \\
\hline
\end{tabular}

${ }^{*}$ Normal value $<3$.

$\dagger$ Immunodiffusion was measured as a dilution of serum in which a precipitin could still be seen.

Table 2 Renal biopsy results in patients with anti-Sm antibodies*

\begin{tabular}{llll}
\hline Grade & $\begin{array}{l}\text { Anti-Sm } \\
\text { positive }\end{array}$ & $\begin{array}{l}\text { Anti-Sm } \\
\text { negative }\end{array}$ & $p$ Value \\
\hline Normal (I) & 0 & 0 & NS \\
Mesangial (IIa, IIb) & 3 & 3 & NS \\
Focal and segmental (III) & 2 & 5 & NS \\
Diffuse proliferative (IV) & 0 & 5 & $<0.05$ \\
Membranous (V) & $5 \dagger$ & 1 & $<0.05$
\end{tabular}

${ }^{*}$ Renal biopsy data were btained from 23 of the patients with SLE and classified according to Appel et al. ${ }^{10}$

tThose with a membranous component included two with some evidence of proliferative change and one with a focal change.

eight of 11 Afro-Carribean patients $(73 \%)$, and three of seven Asian patients (43\%).

The presence of anti-Sm antibodies did not correlate with any features of SLE; in particular there was no correlation with skin, central nervous system, or renal disease. Of the 23 patients in whom renal biopsy was graded, ${ }^{10}$ however, the presence of anti-Sm antibodies was negatively associated with a pure diffuse proliferative glomerulonephritis $(p<0.05)$ and positively associated with a membranous component to the glomerulonephritis $(p<0 \cdot 05)$ (Table 2).

\section{Discussion}

These data demonstrate that immunoaffinity chromatography with monoclonal antibodies produces large quantities of $\mathrm{Sm}$ antigen without significant 
contamination. The peptide composition of purified $\mathrm{Sm}$ compares well with that extracted by affinity chromatography, ${ }^{511}$ biochemical purification, ${ }^{12}$ and immunoprecipitation. ${ }^{13}$

In an ELISA study for anti-Sm antibodies Maddison et al immunopurified $\mathrm{Sm}$ from RNAse digested thymus extract using human polyclonal antisera. ${ }^{14}$ Anti-Sm antibodies were detected in patients with SLE but also in those with rheumatoid arthritis and other autoimmune diseases. Our data show that extraction by human polyclonal antisera leads to copurification of non-specifically bound proteins (Fig. 1), which could result in false positive tests. These data demonstrate that the disease specificity of anti-Sm antibodies for SLE in sensitive ELISA assays depends on antigenic purity.

Pollard and Tan used biochemically purified antigen in an ELISA and found anti-Sm antibodies restricted to patients with SLE, but also in one patient with diabetes mellitus and a facial rash. ${ }^{15}$ The use of the monoclonal antibody to purify Sm antigen by affinity chromatography produces larger quantities of pure $\mathrm{Sm}$ than biochemical techniques, and its use in the ELISA shows that only patients with SLE have detectable IgG anti-Sm antibodies. Thus this method will provide an assay which could be readily used in clinical practice.

Comparison of ELISA and immunodiffusion showed six samples positive for anti-Sm by ELISA which were negative by immunodiffusion. Of these, four had anti-Sm antibodies in their serum detected by immunodiffusion either in previous or subsequent samples, implying that the ELISA is more sensitive than immunodiffusion. All four samples also had detectable anti-RNP antibodies by immunodiffusion, which may obscure anti-Sm precipitins. ${ }^{16}$

Early studies suggested a link between anti-Sm antibodies and cerebral SLE, ${ }^{17}$ though these antibodies were not confirmed as markers for central nervous system disease in the lupus population as a whole. ${ }^{18}$ Comparison of the 52 patients in this study failed to delineate any association between anti-Sm antibodies and clinical characteristics of SLE. Similarly, no lupus features were ascribed to the presence of anti-Sm antibodies when using immunoprecipitation to detect these antibodies. ${ }^{19}$ These increasingly sensitive assays may well include a more representative sample of the lupus population in the positive group, hence removing any dissimilarity between populations.

A pure diffuse proliferative glomerulonephritis was not detected in any patient with anti-Sm antibodies, confirming results from two studies that compared the presence of renal disease with autoantibody profile. Winn et al found only one of 23 patients with anti-Sm antibodies with this severe proliferative renal change, ${ }^{20}$ and Venables et al $\stackrel{\square}{\circ}$ showed that the presence of antibodies to the soluble cellular antigens in general was commonly $\stackrel{\vec{s}}{\rightarrow}$ noted in association with a membranous glomerulo- 0 nephritis. ${ }^{21}$ In murine models of SLE only the MRL음 strain develops anti-Sm antibodies, and these $\frac{5}{5}$ animals have a less severe glomerulonephritis than $\stackrel{\mathbb{Q}}{\Omega}$ the NZB/W mice, which only have anti-DNA antibodies. ${ }^{22}$

These studies demonstrate a higher incidence of $\vec{\circ}$ anti-Sm antibodies than the $4-7 \%$ reported in the $\overrightarrow{\vec{\omega}}$ English studies 2324 and the $17 \%$ in the Indian $\stackrel{ }{\circ}$ population $^{25}$ and are more in line with the prevalence in the USA lupus population. ${ }^{26}$ Nevertheless, the wide racial difference in the incidence of anti-Sm. antibodies has been confirmed. ${ }^{23}$ Whether this is the $\vec{O}$ result of genetic differences or the effect of some $\stackrel{\infty}{N}$ environmental factor in the initiation of the anti-Sm antibody response remains to be understood.

This work was supported by the Arthritis and Rheumatism Council.

References

1 Tan E M, Kunkel H G. Characteristics of a soluble nucle antigen precipitating with sera of patients with systemic lup⿶s erythematosus. J Immunol 1966; 96: 464-71.

2 Sharp G S, Irvin W S, LaRoque R L, et al. Association autoantibodies to different nuclear antigens with clinical patterns of rheumatic diseases and responsiveness to therapy. $J \overline{\bar{O}}$ Clin Invest 1971; 50: 350-9.

3 Mattioli M, Reichlin M. Characterisation of a soluble nuclear $\frac{(\mathbb{D}}{8}$ ribonucleoprotein antigen reactive with systemic lupus erythematosus sera. J Immunol 1971; 107: 1281-90.

4 Buchanan R R C, Venables P J W, Morgan A, Stains N A, כ Smith P R, Maini R N. Separation of two molecular species of the $\mathrm{Sm}$ antigen by affinity chromatography with murine monoclonal and human antinuclear antibodies. Clin Exp Immunol 1983; 51: 8-16.

5 Billings $\mathrm{P}$ B, Hoch S O. Isolation of intact Sm/RNP antigens from rabbit thymus. $J$ Immunol 1983; 131: 347-51.

6 Williams D G, Stocks M R, Smith P R, Venables P J W, MainiR N. Murine lupus monoclonal antibodies define five epitopes? on two different Sm polypeptides. Immunology 1986; 58: 495-500.

7 Laemmli U K. Cleavage of structural proteins during the $\stackrel{\circ}{\supset}$ assembly of the head of bacteriophage T4. Nature $1970 ; 227: \square$ 680-5.

8 Tan E M, Cohen A S, Freis J F, et al. The 1982 revised ARA criteria for the classification of systemic lupus erythematosus. N Arthritis Rheum 1982; 25: 1271-7.

$\overline{9}$ Śmith P R, Williams D G, Venables P J W, Maini R N. O Monoclonal antibodies to the Sjögren's syndrome associated N antigen SS-B (La). J Immunol Methods 1985; 77: 63-76.

10 Appel G B, Silva F G, Pirani C L, Meltzer J I, Estes D. Renal involvement in systemic lupus erythematosus. A study of 56 patients emphasising histological classification. Medicine (Balti $-\frac{\mathrm{C}}{\mathrm{D}}$ more) 1978; 57: $371-410$.

11 Billings $P$ B, Hoch $S \mathrm{O}$. Characterization of $U$ small nuclear RNA-associated proteins. J Biol Chem 1984; 259: 12850-6. T

12 Lerner M R, Steitz J A. Antibodies to small nuclear RNAs? complexed with proteins are produced by patients with systemic lupus erythematosus. Proc Natl Acad Sci USA 1979; 76: 5495-9. 
13 Connor G E, Nelsom D, Wisniewolski R, Lahita R G, Blobel G, Kunkel H G. Protein antigens of the RNA-protein complexes detected by anti-Sm and anti-RNP antibodies found in the serum of patients with systemic lupus erythematosus and related disorders. J Exp Med 1982; 156: 1475-85.

14 Maddison P J, Skinner R P, Vlachoyiannopoulos P, Brennand D M, Hough D. Antibodies to RNP, Sm, Ro(SSA), La(SSB) detected by ELISA: their specificity and interrelations in connective tissue disease sera. Clin Exp Immunol 1985; 62: 337-45.

15 Pollard K M, Tan E M. Purification of the Sm nuclear autoantigen. Detection and clinical significance of IgM antibody. Clin Exp Immunol 1985; 60: 586-96.

16 Nakamura R M, Peebles C L, Rubin R L, Molden D P, Tan E M. Autoantibodies to nuclear antigens (ANA). Chicago: American Society of Clinical Pathologists Press, 1985.

17 Winfield J B, Brunner C M, Koffler D. Serologic studies in patients with systemic lupus erythematosus and central nervous system dysfunction. Arthritis Rheum 1978; 21: 289-94.

18 Barada F A, Andrews B S, Davis J S, Taylor R P. Antibodies to $\mathrm{Sm}$ in patients with systemic lupus erythematosus. Correlation of Sm antibody titres with disease activity and other laboratory parameters. Arthritis Rheum 1981; 24: 1236-44.

19 Williamson G G, Pennebaker J, Boyle J A. Clinical characteristics of patients with rheumatic disorders who possess antibodies against ribonucleoprotein particles. Arthritis Rheum 1983; 26: 509-15.
20 Winn D M, Wolfe J F, Lindberg D A, Fristoe F H, Kinsland L, Sharp G C. Identification of a clinical subset of systemic lupus erythematosus by antibodies to the $\mathrm{Sm}$ antigen. Arthritis Rheum 1979; 22: 1334-7.

21 Venables P J W, Tung Y, Woodrow D F, Moss J, Maini R N. Relationship of precipitating antibodies to soluble cellular antigens and histologically defined renal lesions in systemic lupus erythematosus. Ann Rheum Dis 1983; 42: 17-22.

22 Andrews B S, Eisenberg R A, Theofilopoulos A N, et al. Spontaneous murine lupus like syndromes. Clinical and immunopathological manifestations in several strains. J Exp Med 1978; 148: 1198-215.

23 Bernstein R M, Bunn C C, Hughes G R V, Francoeur A M, Mathews M B. Cellular protein and RNA antigens in autoimmune disease. Mol Biol Med 1984; 2: 105-20.

24 Gordon T, Maddison P J, Isenberg D A. Rapid development of cerebral atrophy in systemic lupus erythematosus. Br J Rheumatol 1986; 25: 296-9.

25 Malaviya A N, Misra R, Bannerjee S, et al. Systemic lupus erythematosus in North Indian Asians. A prospective analysis of clinical and immunological features. Rheumatol Int 1986; 6: 97-102.

26 Notman D D, Kurata N, Tan E M. Profiles of antinuclear antibodies in systemic rheumatic diseases. Ann Intern Med 1975; 83: 464-9. 